\title{
Communication \\ pH-Responsive Hollow Polymeric Microspheres from Irradiated Cyclic Ether Aqueous Solution
}

\author{
Chuhong Yu, Jing Peng * ${ }^{\mathbb{C}}$, Jiuqiang Li and Maolin Zhai * \\ Beijing National Laboratory for Molecular Sciences, Radiochemistry and Radiation Chemistry Key Laboratory of \\ Fundamental Science, Key Laboratory of Polymer Chemistry and Physics of the Ministry of Education, College of \\ Chemistry and Molecular Engineering, Peking University, Beijing 100871, China; Nellie.yu@halmana.com (C.Y.); \\ jqli@pku.edu.cn (J.L.) \\ * Correspondence: jpeng@pku.edu.cn (J.P.); mlzhai@pku.edu.cn (M.Z.); \\ Tel.: +86-10-6275-7193 (J.P.); +86-10-6275-3794 (M.Z.)
}

check for updates

Citation: Yu, C.; Peng, J.; Li, J.; Zhai, M. pH-Responsive Hollow Polymeric Microspheres from Irradiated Cyclic Ether Aqueous Solution. Appl. Sci. 2021, 11, 8652. https://doi.org/ 10.3390/app11188652

Academic Editor:

Dorota Swiatla-Wojcik

Received: 28 August 2021

Accepted: 15 September 2021

Published: 17 September 2021

Publisher's Note: MDPI stays neutral with regard to jurisdictional claims in published maps and institutional affiliations.

Copyright: (c) 2021 by the authors. Licensee MDPI, Basel, Switzerland. This article is an open access article distributed under the terms and conditions of the Creative Commons Attribution (CC BY) license (https:// creativecommons.org/licenses/by/ $4.0 /)$.

\begin{abstract}
Smart hollow polymeric microspheres have been widely applied in various fields such as controlled release, drug delivery, catalysis, and so on. Herein, a facile, green and one-step templatefree method is introduced for preparing $\mathrm{pH}$-responsive hollow polymeric microspheres via gamma irradiation of cyclic ether aqueous solution. The hollow polymeric microspheres are synthesized by radiation-induced polymerization and following the self-assembly and self-organization of amphiphilic polymer with cyclic ethers as monomers in water. SEM, TEM, micro-FTIR, and NMR confirmed the morphology and structures of the resultant microspheres. The confocal laser scanning microscope was used to investigate the stimuli-responsiveness and release behavior of hollow microspheres using 1-pyrene carboxaldehyde as a hydrophobic molecule model. The well-defined hollow polymeric microspheres with an average diameter of ca. $2.6 \mu \mathrm{m}$ or $1.6 \mu \mathrm{m}$ were prepared directly from dicyclohexal-18-crown-6 or tetraphydropyrane aqueous solution, respectively. The prepared hollow microspheres exhibit obvious $\mathrm{pH}$ stimuli-responsiveness and can release the encapsulated hydrophobic molecules when $\mathrm{pH}$ is higher than 5.0. Moreover, the reversible morphology transition between hollow microspheres and micelles makes the prepared hollow polymeric microspheres potentially suitable for a wide range of applications, including removal of dyes, oil field engineering, and biomedical fields.
\end{abstract}

Keywords: $\gamma$-irradiation; cyclic ethers; stimuli-responsiveness; hollow microspheres

\section{Introduction}

Stimuli-responsive hollow particles, especially hollow micro-sized or nano-sized spheres, continue to attract major interest because they have wide potential applications in fields such as dye precipitation [1], catalysis [2,3], sensors [4-6], and especially controlled delivery systems [7-10]. Early studies on hollow polymeric microspheres were conducted by Caruso et al. [11]. Up to today, many 'smart' hollow polymeric microspheres have been prepared via various methods such as the template method [11], the microencapsulation method [12], and the self-assembly layer-by-layer method [13], which are usually based on pre-prepared stimuli-responsive copolymers. Though having the advantage of controlling the supramolecular architectures and functions by constructing copolymer structures, these methods commonly require multi-step and complex procedures to synthesize the stimuliresponsive copolymers. Moreover, the complicated bottom-up processes and scrupulous core-removing techniques are also required [14,15]. All of these would restrict the practical applications of those methods in fabricating 'smart' hollow microspheres.

As a facile and efficient route to generate novel polymeric materials, $\gamma$-irradiation has attracted increasing interest since the preparation can be carried out without any initiators or catalysts under mild conditions [16-18]. Compared with chemical-initiated polymerization, radiation-induced polymerization allows decoupling initiation kinetics from the 
effects of temperature on the induced chemical reactions, particularly on chain propagation and transfer reactions for polymer synthesis. This makes it possible to follow polymerization kinetics under stationary and various experimental conditions, thus reducing the risks of chain branching and the products with a high purity could be obtained easily [18]. Gamma irradiation has enough energy to ionize atoms and molecules and could provide high penetration depth in matter. Therefore, gamma irradiation has been widely used in the synthesis of hydrogels [16], nanocomposites [17], and so on. However, most studies on the radiation synthesis of hollow microspheres employ water-in-oil microemulsions or micelles as templates $[19,20]$, and the following cross-linking of the shells occurs during irradiation to fabricate stable hollow structures. In addition, the multi-step synthesis processes are still required, including the preparation and removal of the templates. According to our knowledge, despite numerous reports about the preparation of 'smart' hollow microspheres by using various methods, one-step construction starting from small molecules without any templates is still lacking.

Moreover, among the enormous interest in developing advanced properties of the 'smart' hollow microspheres, one of the emerging areas is the combination of the reversible controlled-structure transition with delivery application [21]. The triggered transition from large-scale objects to constituent particles permits on-demand release of entrapped matters, which is important for applications in industries such as oil field engineering and biomedical fields. Therefore, it is highly desirable to develop a simple route to prepare stimuli-responsive hollow microspheres with reversible structure transition abilities.

In this work, we reported the construction of well-defined hollow microspheres via a one-step $\gamma$-irradiation procedure using simple cyclic ethers without double bonds as monomers in aqueous solution. The possible formation mechanism of hollow microspheres was proposed. When irradiated in water, due to the reaction with $\mathrm{OH}$ radicals, the rings of cyclic ethers were opened to be converted to amphiphilic polymers containing functional groups $(\mathrm{OH}, \mathrm{CHO}$, and $\mathrm{COOH}$ groups), which was identified in our previous work [22]. Then, the amphiphilic polymers would be self-organized into hollow microspheres at a suitable irradiation time. Furthermore, the $\mathrm{pH}$ stimuli-responsiveness, the controlled morphology transition, and the possibility as controlled delivery systems of the prepared hollow microspheres were studied in detail via a combination method of confocal laser scanning microscope (CLSM) and labeling of dyes. The radiation-synthesized hollow polymeric microspheres exhibit obvious $\mathrm{pH}$ stimuli-responsiveness and can release the encapsulated hydrophobic molecules at $\mathrm{pH}$ above 5.0. Moreover, the reversible disassembly/assembly behavior between hollow microspheres and amphiphilic polymer micelles could be repeated several times.

\section{Materials and Methods}

\subsection{Materials}

Dicyclohexal-18-crown-6 (DCH18C6) (>98.0\%) was purchased from Tokyo Chemical Industry Co., Ltd (Tokyo, Japan ). Tetrahydropyrane (99\%) was purchased from Acros Organics Co., Ltd. All chemicals were analytical pure reagents and used as received.

\subsection{Preparation of Polymeric Microspheres}

Typically, the irradiation of $0.01 \mathrm{~mol} \mathrm{~L}^{-1}$ DCH18C6 aqueous solution was carried out in air using gamma rays from ${ }^{60} \mathrm{Co}$ source with irradiation time ranging from 56 to $278 \mathrm{~h}$ (dose rate: $30 \mathrm{~Gy} \mathrm{~min}^{-1}$ ). After irradiation, precipitates were produced. The yield of hollow microspheres was calculated as:

$$
\text { yield of hollow microspheres }(\%)=\left(\mathrm{m}_{\mathrm{h}} / \mathrm{m}_{\mathrm{s}}\right) \times 100
$$

where $m_{h}$ and $m_{s}$ refer to the masses of dry hollow microspheres and initial cyclic ether in the aqueous solution, respectively. 
The core fraction was calculated as:

$$
\text { core fraction }(\%)=\left(\mathrm{V}_{\mathrm{c}} / \mathrm{V}_{\mathrm{m}}\right) \times 100
$$

where $\mathrm{V}_{\mathrm{c}}$ and $\mathrm{V}_{\mathrm{m}}$ refer to the average volumes of the hollow cores and the whole microspheres, respectively.

\subsection{Characterization}

\subsubsection{Morphology Observation and Average Molecular Weight}

The morphology of products was observed using a scanning electron microscope (SEM) (NanoSEM 430, FEI, Hillsboro, OR, USA) with a voltage of $15 \mathrm{kV}$ and a transmission electron microscopy (TEM) (Tecnai F20, FEI, Hillsboro, OR, USA) at an acceleration voltage of $200 \mathrm{kV}$ using a standard resin-embedding protocol to isolated thin films. The size distribution and average size of microspheres were determined by measuring about 300 particles using the SEM observation. A confocal laser scanning microscope (CLSM) (A1r, Nikon, Minato Ward, Tokyo, Japan) with a light field mode was used to get the optical micrograph of products.

The number-average molecular weight (Mn) and the polydispersity index (PDI) of the polymer were determined by gel permeation chromatography (GPC), which was performed with a Waters HPLC system using DMF as an eluent. The separation was performed on Waters Styragel HR4 and HR6 columns $(7.8 \mathrm{~mm} \times 300 \mathrm{~mm})$ at $27{ }^{\circ} \mathrm{C}$ with a flow rate of $1 \mathrm{~mL} \mathrm{~min}^{-1}$. Monodisperse polymethylmethacrylate standards were used to calibrate the molecular weights.

The hydrodynamic diameter $\left(D_{h}\right)$ of the polymer micelles in water was determined by dynamic laser scattering (DLS) using a Nano ZS Zetasizer equipped with a He/Ne laser light source $(633 \mathrm{~nm}, 4.0 \mathrm{~mW})$. The measurements were made at a scattering angle of $90^{\circ}$. Before each data collection, the samples were allowed to equilibrate for $2 \mathrm{~min}$ at each temperature. The stock solutions were filtered through a Millipore $0.45 \mathrm{~mm}$ PVDF filter into a dust-free vial. The mean particle size was determined by the intensity of particles and the polydispersity index (PDI) was obtained by the cumulant method.

\subsubsection{Chemical Structure Analysis}

Micro-Fourier transform infrared (Micro-FTIR) spectra were recorded at room temperature with a resolution of $4 \mathrm{~cm}^{-1}$ by a micro-FTIR spectrometer (Nicolet iN10 MX).

${ }^{1} \mathrm{H}$ nuclear magnetic resonance $\left({ }^{1} \mathrm{H} \mathrm{NMR}\right)$ spectra were recorded on a Bruker Avance III $500 \mathrm{MHz}$ NMR spectrometer, using DMSO-d6 as the solvent and TMS as the internal standard.

X-ray photoelectron spectroscopy (XPS) spectra were recorded on an AXIS-Ultra Imaging Photoelectron Spectrometer from Kratos Analytical Ltd. using monochromatic $\mathrm{Al}-\mathrm{K} \alpha$ radiation in a vacuum of $2 \times 10^{-8} \mathrm{~Pa}$ and low energy electron flooding for charge compensation. The data were converted into a VAMAS file format and imported into a CASA XPS software package for manipulation and curve fitting.

\subsubsection{Measurement of Performance of Hydrophobic Carriers}

The encapsulation feasibility of the resultant products was determined by CLSM (A1r, Nikon, Minato Ward, Tokyo, Japan) using Rhodamine B (RhB) as a hydrophilic model and 1-pyrene carboxaldehyde (1-PChyde) as a hydrophobic probe. The hollow microspheres were simply immersed in 1-PChyde ether solution and RhB aqueous solution for a few minutes, respectively. Then, the labeled microspheres were centrifuged, re-dispersed in water, and the fluorescence imaging observation was performed by CLSM. Images were taken under conditions as follows: $60 \times$ immersion lens with a resolution of $2048 \times 2048$ and a speed of $8 \mathrm{~s}$ per frame, $40 \%$ laser power for 1-PChyde (ex: $405 \mathrm{~nm}$, em: $425-475 \mathrm{~nm}$ ), and $60 \%$ laser power for RhB (ex: $543 \mathrm{~nm}$, em: 555-650 nm), and fluorescent images were processed and analyzed using NIS-element software. 


\section{Results and Discussions}

\subsection{Characteriziation of Microshpheres and Possible Formation Mechanism}

Radiation-induced synthesis can be carried out in aqueous systems, which minimizes the use of organic solvents and the need for separation and purification of the final product. As can be seen, by only one-step $\gamma$-irradiation, well-defined hollow microspheres with the average diameter of ca. $2.6 \mu \mathrm{m}$ and narrow size distribution were prepared successfully from DCH18C6 aqueous solution (Figure 1). In addition, no other organic or inorganic templates were used to obtain the hollow structure via this approach. The relationship between the yield of hollow microspheres and irradiation time was then determined by a gravimetric method. As can be seen from Figure 2a, the yield of hollow microspheres increased linearly and dramatically with increasing irradiation time, and DCH18C6 was completely converted to hollow microspheres after $167 \mathrm{~h}$ of irradiation. Further prolonging the irradiation time did not influence the morphology, and only slightly reduced the average diameters of the prepared hollow microspheres (Figure S1).

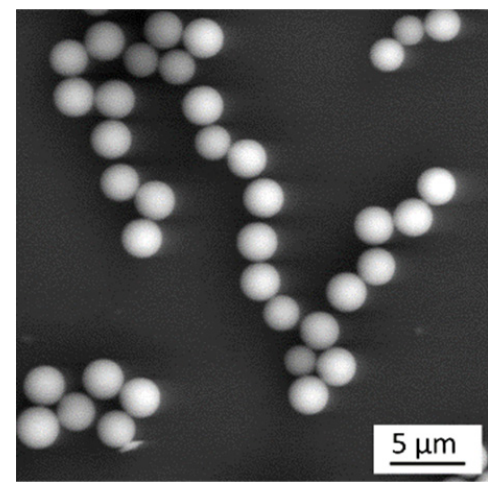

(a)

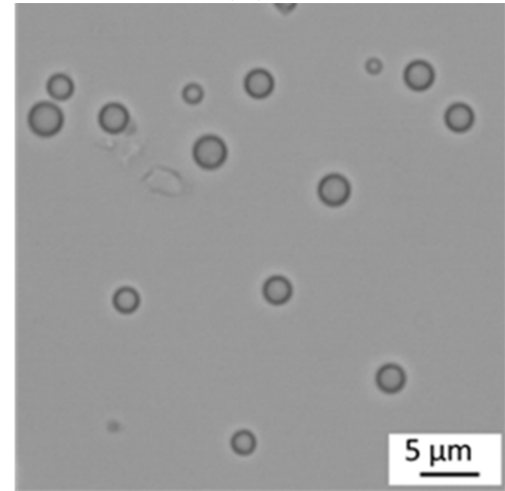

(c)

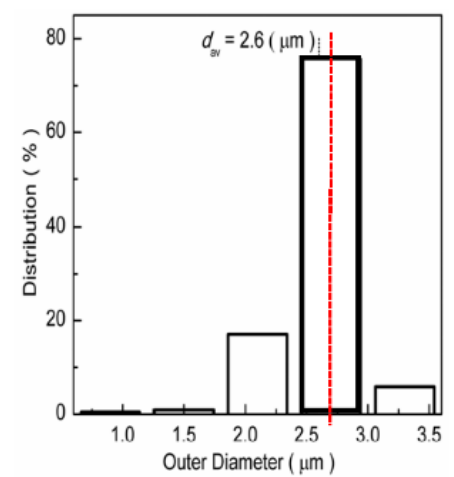

(b)

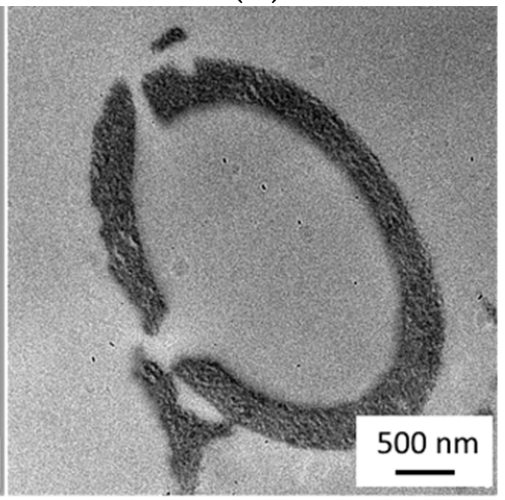

(d)

Figure 1. The SEM image (a), size distribution (b), and CSLM optical micrograph (c) of the hollow microspheres obtained by irradiating $0.01 \mathrm{~mol} \mathrm{~L}^{-1}$ DCH18C6 for $167 \mathrm{~h}$, respectively, and TEM image of the ultra-thin section of the hollow microspheres (d).

The chemical structure of the hollow microspheres was determined by micro-FTIR, ${ }^{1} \mathrm{H}$ NMR, and XPS (Figures S2-S4). It was found that the polymer consists of a hydrophobic main chain and hydrophilic side chains containing oligo (ethylene glycol) and functional groups $(\mathrm{OH}, \mathrm{CHO}$, and $\mathrm{COOH}$ groups), which is similar to the structure of the amphiphilic polymer reported in our previous work [22], but the hollow microspheres had much higher average molecular weight $\left(\mathrm{Mn}=2.69 \times 10^{6}\right)$ than that of amphiphilic polymers $(\mathrm{Mn}=1050)$. Thus, we suggest that the hollow microspheres were prepared from selforganization of amphiphilic polymer micelles obtained by irradiating DCH18C6 aqueous solution (Scheme 1). When the DCH18C6 was exposed to gamma irradiation in a dilute aqueous solution, most of the radiation energy was absorbed by water. Then, short-lived 
reactive species, including $\cdot \mathrm{OH}$ radicals, $\mathrm{H}$-atoms, and hydrated electrons, were formed. The C-O bonds of cyclic ethers could be cleaved during irradiation in water due to the reaction with $\cdot \mathrm{OH}$ radicals from the radiolysis of water, and intermediate species containing end $\mathrm{C}=\mathrm{C}$ groups were produced consequently [23]. These intermediate species would polymerize to form amphiphilic polymers with hydrophobic backbones, hydrophilic side chains containing oligo (ethylene glycol), and functional groups $(\mathrm{OH}, \mathrm{CHO}$, and $\mathrm{COOH}$ groups), and the resultant amphiphilic polyDCH18C6 (named as am-DCH18C6) existed in the water as core-shell micelles. Then, with the increase of irradiation time, the amDCH18C6 micelles could be further self-organized to form the hollow microspheres, and crosslinking of polymer micelles perhaps occurred simultaneously [18]. It was found that, in the presence of $\mathrm{N}_{2} \mathrm{O}$, the hydrated electrons from radiolysis of water could be changed to $\mathrm{OH}$ radicals. The yield of hollow microspheres increased from $51.9 \pm 0.7 \%$ to $85.5 \pm 0.7 \%$ at irradiation time of $111 \mathrm{~h}$, indicating that the $\cdot \mathrm{OH}$ radicals play a key role in the formation of hollow microspheres. Moreover, the yield of hollow microspheres increased with decreasing dose rate. It is attributed to the fact that the lower dose rate favors an intermolecular recombination due to a lower probability for the presence of two or more radical sites on a single polymer chain in the steady state [24].
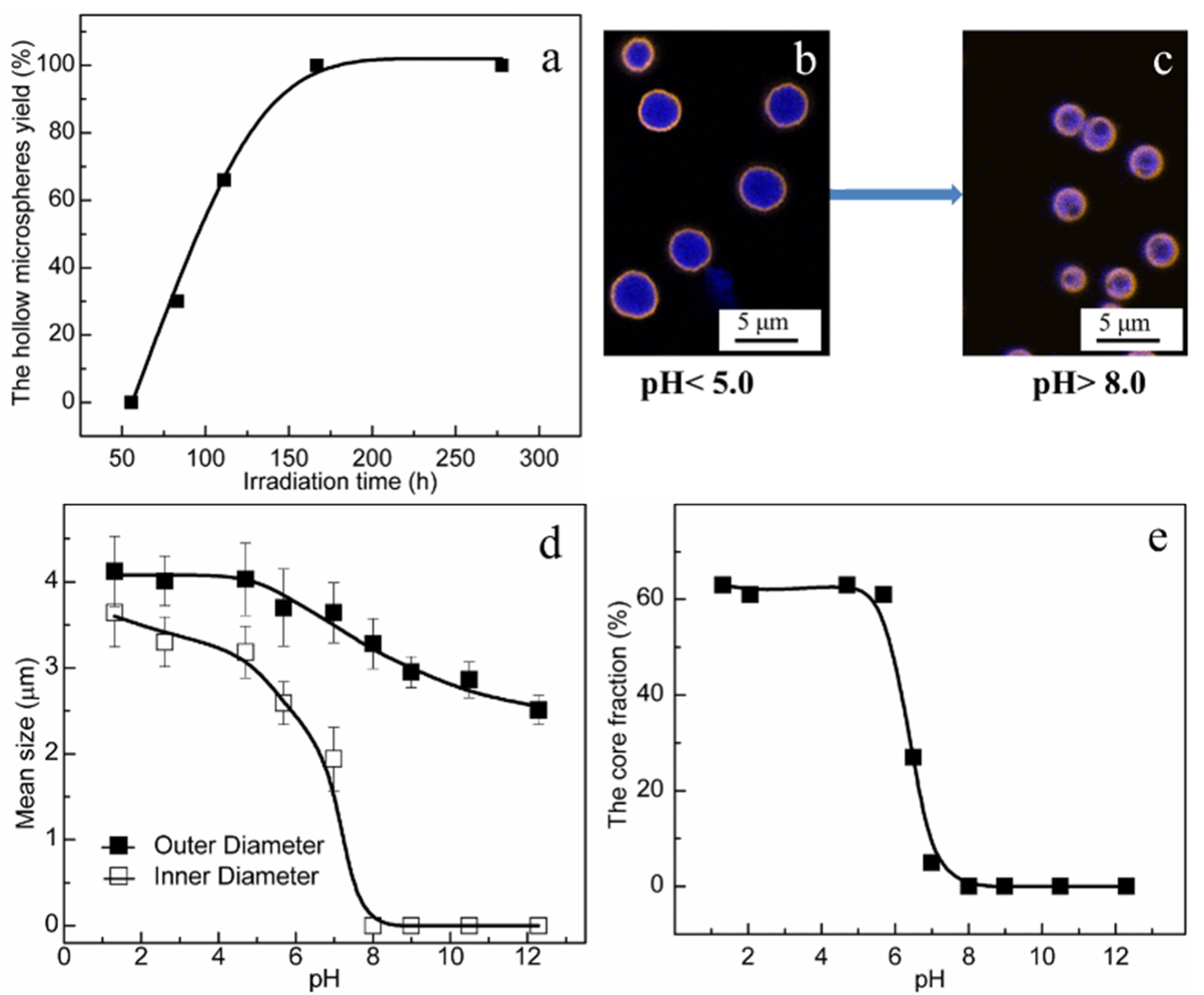

Figure 2. The relationship between the yield of hollow microspheres and irradiation time (a), the CLSM image of the hollow polymeric microspheres prepared by irradiating DCH18C6 aqueous solution for $167 \mathrm{~h}$ at $\mathrm{pH}<5$ (b) and $\mathrm{pH}>8$ (c), and the change in mean size (d) and core fraction (e) with $\mathrm{pH}$ for the hollow microspheres measured by CLSM. 


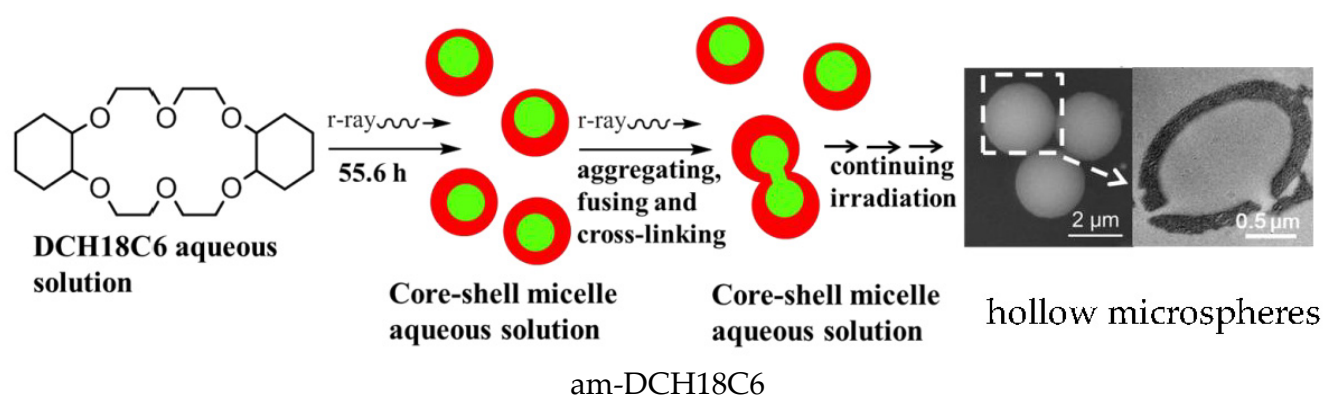

Scheme 1. Schematic representation for the synthesis of hollow microspheres from DCH18C6 via one-step $\gamma$-irradiation in water.

Similarly, tetraphydropyrane, which has a much simpler cyclic ether structure, was also employed to prepare hollow microspheres via one-step $\gamma$-irradiation in water. After $167 \mathrm{~h}$ of irradiation, well-defined hollow microspheres with an average diameter of ca. $1.6 \mu \mathrm{m}$ and narrow size distribution could be efficiently prepared (Figure S5). This indicates that the amphiphilic polymers of tetraphydropyrane (am-tetraphydropyrane) could be synthesized as well. However, the structure and hydrophilicity of the side chains vary by the different structures of the cyclic ethers. In this case, the structure of the cyclic ethers will have an obvious effect on the self-assembly of the prepared amphiphilic polymers, which can strongly affect the morphology of the consequent supramolecular objects. For DCH18C6, the am-DCH18C6 micelle existed with a core-shell structure and for tetraphydropyrane, the am-tetraphydropyrane micelle with a flower morphology was obtained [22]. In addition, these amphiphilic polymer micelles could be further changed to hollow microspheres with the increase of irradiation time. Therefore, it is a general and efficient approach to prepare hollow microspheres by one-step $\gamma$-irradiation employing a range of cyclic ethers with appropriate structures which have some solubility and hydrophobicity in water.

\section{2. $\mathrm{pH}$-Trigged Molecular Release}

By using a combination method of CLSM and labeling of dyes, we could investigate the hydrophobicity of the hollow microspheres. As shown in Figure 2b, the hydrophilic dye was only confined to the shells, indicating that the prepared hollow microspheres possessed hydrophilic shells and hydrophobic cores. Moreover, when the $\mathrm{pH}$ was lower than 5.0, the hydrophobic dye could be easily encapsulated into the hollow cores of the microspheres. Notably, different from other tedious methods for matter encapsulation, immersion was a much easier way and was expected to be suitable for various hydrophobic matters. However, the situation was very different when the solution $\mathrm{pH}$ increased from 5.0 to about 8.0. The CLSM image showed that the hollow microspheres shrank and less hydrophobic dye was encapsulated (Figure 2c). These results may be attributed to the $\mathrm{pH}$ stimuli-responsiveness of the hollow microspheres. Therefore, the relationship between the morphology of the obtained hollow microspheres and the solution $\mathrm{pH}$ was investigated in detail in a wide $\mathrm{pH}$ range.

As shown in Figure 2d, when the $\mathrm{pH}$ was lower than 5.0, the hollow microspheres remained swollen. Herein, the hydrophobic dye could be encapsulated and taken away from the aqueous solution. However, the sharp shrinkage of the outer and inner diameters occurred immediately when the $\mathrm{pH}$ was higher than 5.0. In addition, the core fraction of the hollow microspheres also decreased simultaneously (Figure 2e). In fact, the core fraction decreased extremely from about $70 \%$ to nearly $0 \%$, when the $\mathrm{pH}$ increased from about 1.0 to 8.0 . Therefore, the encapsulated hydrophobic dye could be rapidly squeezed out of the hollow cores and released in aqueous solution by simply adjusting the solution $\mathrm{pH}$. Moreover, no further shrinkage was observed at $\mathrm{pH}$ above 8.0.

This $\mathrm{pH}$ stimuli-responsiveness may be ascribed to the alteration of ionization degree of the prepared amphiphilic polymers bearing $\mathrm{COOH}$ groups (pKa 4.80 ) [21]. When the 
$\mathrm{pH}$ was less than 5.0, only a few $\mathrm{COOH}$ groups were deprotonated and the hydrogen bonds among the obtained amphiphilic polymers promoted the formation of compact aggregates. With the increase of $\mathrm{pH}$, the obtained polymers existed in the more stretched conformation due to the deprotonation of the $\mathrm{COOH}$ groups, leading to the formation of the incompact aggregated structures with disappearing hollow cores [25]. The as-prepared $\mathrm{pH}$-responsive hollow microspheres are possibly applicable as a drug delivery in the target tissues or cells, e.g., intestine ( $\mathrm{pH}$ 8.4) or endosome ( $\mathrm{pH}$ 6.0-6.5) [7].

Fascinatingly, when the labeled hollow microspheres were subjected to $1 \mathrm{~mol} \mathrm{~L}^{-1}$ $\mathrm{KOH}$ aqueous solution, they decomposed in seconds, leaving the hydrophobic dye completely released in water (the inset of Figure 3a). Moreover, TEM (Figure 3a) and DLS analysis showed that the hollow microspheres were disassembled to well-defined core-shell aggregates with $\mathrm{a}<\mathrm{D}_{\mathrm{h}}>$ of $133.4 \mathrm{~nm}$ (Figure S6). This behavior might be attributed to the intensive weakening of interactions among amphiphilic polymers by adding strong alkane. Moreover, after $\mathrm{KOH}$ had been removed via a dialysis process, the core-shell aggregates could be reassembled back to hollow microspheres with an average diameter of ca. $1.9 \mu \mathrm{m}$ by simply irradiating the aqueous solution (Figure $3 \mathrm{~b}$ and Figure S7). It indicated the self-organization of the hydrophobic segments of the obtained core-shell micelles under irradiation so as to minimize their contact with surrounding water. Notably, this reversible disassembly/assembly behavior between dispersing core-shell micelles and hollow microspheres could be repeated for several times. Therefore, the reversible encapsulation/release of the hydrophobic matters can be expected for the prepared hollow microspheres. In this respect, these novel hollow microspheres show particular promise for advanced applications in oil field engineering and biomedical fields, where structural transitions between constituent particles and large-scale materials are desperately required.
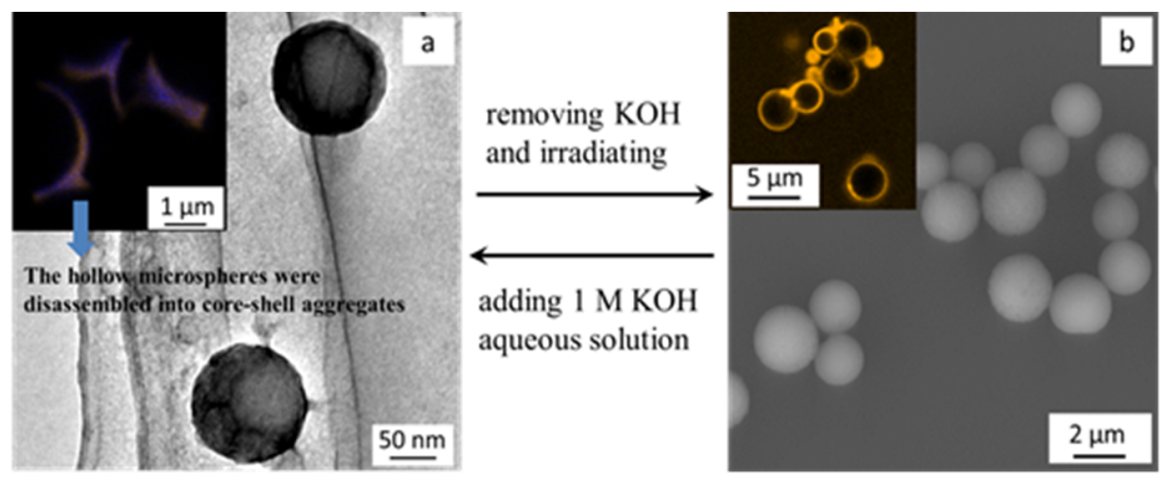

Figure 3. The TEM image of the core-shell aggregates obtained from the disassembly of the hollow microspheres in $1 \mathrm{~mol} \mathrm{~L}^{-1} \mathrm{KOH}$ aqueous solution (the inset of 3a is the CLSM image of the hollow microspheres in $1 \mathrm{~mol} \mathrm{~L}^{-1} \mathrm{KOH}$ aqueous solution) (a), and the SEM and CLSM (the inset of 3b) images of the hollow microspheres obtained by irradiating core-shell am-DCH18C 6 for $56 \mathrm{~h}$ after removing $\mathrm{KOH}(\mathbf{b})$.

\section{Conclusions}

A green, simple, and one-step template-free procedure for the construction of $\mathrm{pH}$ responsive hollow microspheres via $\gamma$-irradiation was developed using cyclic ethers, such as DCH18C6 and tetrahydropyrane, as monomers in aqueous solution. The hollow microspheres were prepared from radiation-induced polymerization and self-organization of amphiphilic polymers micelles obtained by irradiating cyclic ethers aqueous solution. The $\mathrm{pH}$-responsive delivery ability and reversible morphology transition between micelles and hollow microspheres made the obtained hollow microspheres applicable as advanced functional materials with controlled structure. It is expected that our work will highlight the importance of $\gamma$-irradiation in the design and construction of novel 'smart' materials via a simple template-free method. 
Supplementary Materials: The following are available online at https:/ / www.mdpi.com/article / 10.3390/app11188652/s1, Figure S1: The SEM image (a), size distribution (b) and the CLSM optical micrograph (c) of the well-defined hollow microspheres obtained by irradiating $0.01 \mathrm{~mol} \mathrm{~L}^{-1}$ DCH18C6 aqueous solution for 278 h, Figure S2: Micro-FTIR spectra of DCH18C6 and the polymer microspheres obtained by irradiating $0.01 \mathrm{~mol} \mathrm{~L}^{-1}$ DCH18C6 aqueous solution for $167 \mathrm{~h}\left(3430 \mathrm{~cm}^{-1}\right.$ $\mathrm{OH}$ stretching vibration, $2930 \mathrm{~cm}^{-1} \mathrm{CH}_{2}$ asymmetric stretching vibration, $2850 \mathrm{~cm}^{-1} \mathrm{CH}_{2}$ symmetric stretching vibration, $1710 \mathrm{~cm}^{-1} \mathrm{C}=\mathrm{O}$ stretching vibration, $1660 \mathrm{~cm}^{-1} \mathrm{C}=\mathrm{C}$ stretching vibration, $1100 \mathrm{~cm}^{-1} \mathrm{C}-\mathrm{O}$ asymmetric stretching vibration, $1000-650 \mathrm{~cm}^{-1} \mathrm{C}-\mathrm{H}$ deformation vibration), Figure S3: ${ }^{1} \mathrm{H}$ NMR spectrum of the amphiphilic polymers obtained by irradiating $0.01 \mathrm{~mol} \mathrm{~L}^{-1}$ DCH18C6 aqueous solution. The inset is ${ }^{1} \mathrm{H}$ NMR spectrum in the range of 8.5-13.5 ppm, Figure S4: XPS spectrum of the hollow microspheres obtained by irradiating $0.01 \mathrm{~mol} \mathrm{~L}^{-1}$ DCH18C6 aqueous solution for $167 \mathrm{~h}$, Figure S5: The SEM image (a) and size distribution (b) of the well-defined hollow microspheres obtained by irradiating $0.01 \mathrm{~mol} \mathrm{~L}^{-1}$ tetrahydropyrane aqueous solution for $167 \mathrm{~h}$, Figure S6: The size distribution of the core-shell am-DCH18C6 micelles obtained from the disassembly of the hollow microspheres obtained by irradiating $0.01 \mathrm{~mol} \mathrm{~L}^{-1}$ DCH18C6 aqueous solution for $167 \mathrm{~h}$ in $1 \mathrm{~mol} \mathrm{~L}^{-1} \mathrm{KOH}$ aqueous solution, Figure S7: The size distribution of the hollow microspheres obtained by reassembling core-shell am-DCH18C 6 after $56 \mathrm{~h}$ of irradiation.

Author Contributions: Conceptualization, J.P. and M.Z.; methodology, C.Y.; validation, J.L.; formal analysis, C.Y.; investigation, C.Y.; data curation, C.Y. and J.L.; writing—original draft preparation, C.Y.; writing-review and editing, J.P. and M.Z.; supervision, J.P. All authors have read and agreed to the published version of the manuscript.

Funding: This research was funded by National Natural Science Foundation of China (NNSFC), Project No.21073008.

Institutional Review Board Statement: Not applicable.

Informed Consent Statement: Not applicable.

Data Availability Statement: Data are included in the article. Additional data are available upon request.

Acknowledgments: The measurements of CLSM were performed at the Analytical Instrumentation Center of Peking University. The help from PKUAIC (Yan Guan) is acknowledged. We would like to give thanks to Xuefeng Fu for her help with the GPC measurement.

Conflicts of Interest: The authors declare no conflict of interest.

\section{References}

1. Raza, S.; Yong, X.; Yang, B.; Xu, R.; Deng, J. Biomass trans-Anethole-Based Hollow Polymer Particles: Preparation and Application as Sustainable Absorbent. ACS Sustain. Chem. Eng. 2017, 5, 10011-10018. [CrossRef]

2. Prieto, G.; Tüysüz, H.; Duyckaerts, N.; Knossalla, J.; Wang, G.-H.; Schüth, F. Hollow Nano- and Microstructures as Catalysts. Chem. Rev. 2016, 116, 14056-14119. [CrossRef] [PubMed]

3. Han, J.; Liu, Y.; Guo, R. Reactive Template Method to Synthesize Gold Nanoparticles with Controllable Size and Morphology Supported on Shells of Polymer Hollow Microspheres and Their Application for Aerobic Alcohol Oxidation in Water. Adv. Funct. Mater. 2009, 19, 1112-1117. [CrossRef]

4. $\mathrm{Hu}, \mathrm{C}$; West, K.R.; Scherman, O.A. Hollow mesoporous raspberry-like colloids with removable caps as photoresponsive nanocontainers. Nanoscale 2016, 8, 7840-7844. [CrossRef] [PubMed]

5. Yan, B.; Han, D.; Boissière, O.; Ayotte, P.; Zhao, Y. Manipulation of block copolymer vesicles using $\mathrm{CO}_{2}$ : Dissociation or "breathing". Soft Matter 2013, 9, 2011-2016. [CrossRef]

6. Song, X.; Bao, B.; Tao, J.; Zhao, S.; Han, X.; Liu, H. Deswelling Dynamics of Thermoresponsive Microgel Capsules and Their Ultrasensitive Sensing Applications: A Mesoscopic Simulation Study. J. Phys. Chem. C 2019, 123, 1828-1838. [CrossRef]

7. Delcea, M.; Möhwald, H.; Skirtach, A.G. Stimuli-responsive LbL capsules and nanoshells for drug delivery. Adv. Drug Deliv. Rev. 2011, 63, 730-747. [CrossRef]

8. Nguyen, T.; Peng, Y.; Seekell, R.P.; Kheir, J.N.; Polizzotti, B.D. Hyperbaric polymer microcapsules for tunable oxygen delivery. J. Control Release 2020, 327, 420-428. [CrossRef]

9. Novoselova, M.V.; Loh, H.M.; Trushina, D.B.; Ketkar, A.; Abakumova, T.O.; Zatsepin, T.S.; Kakran, M.; Brzozowska, A.M.; Lau, H.H.; Gorin, D.A.; et al. Biodegradable Polymeric Multilayer Capsules for Therapy of Lung Cancer. ACS Appl. Mater. Interfaces 2020, 12, 5610-5623. [CrossRef]

10. Zhou, Z.; Wu, W.; Fang, J.; Yin, J. Polymer-based porous microcarriers as cell delivery systems for applications in bone and cartilage tissue engineering. Int. Mater. Rev. 2021, 66, 77-113. [CrossRef] 
11. Caruso, F.; Caruso, R.A.; Möhwald, H. Nanoengineering of Inorganic and Hybrid Hollow Spheres by Colloidal Templating. Science 1998, 282, 1111-1114. [CrossRef]

12. Li, J.; Wang, S.; Liu, H.; Wang, S.; You, L. Preparation and characterization of polystyrene/polycarbonate composite hollow microspheres by microencapsulation method. J. Mater. Sci. 2011, 46, 3604-3610. [CrossRef]

13. Shenoy, D.B.; Antipov, A.A.; Sukhorukov, G.B.; Möhwald, H. Layer-by-Layer Engineering of Biocompatible, Decomposable Core-Shell Structures. Biomacromolecules 2003, 4, 265-272. [CrossRef]

14. Bird, R.; Freemont, T.J.; Saunders, B.R. Hollow polymer particles that are pH-responsive and redox sensitive: Two simple steps to triggered particle swelling, gelation and disassembly. Chem. Commun. 2011, 47, 1443-1445. [CrossRef]

15. Xu, J.; Chen, G.; Yan, R.; Wang, D.; Zhang, M.; Zhang, W.; Sun, P. One-Stage Synthesis of Cagelike Porous Polymeric Microspheres and Application as Catalyst Scaffold of Pd Nanoparticles. Macromolecules 2011, 44, 3730-3738. [CrossRef]

16. Güven, O.; Şen, M.; Karadağ, E.; Saraydın, D. A review on the radiation synthesis of copolymeric hydrogels for adsorption and separation purposes. Radiat. Phys. Chem. 1999, 56, 381-386. [CrossRef]

17. Lu, C.L.; Cheng, Y.R.; Liu, Y.F.; Liu, F.; Yang, B. A facile route to ZnS-polymer nanocomposite optical materials with high nanophase content via gamma-ray irradiation initiated bulk polymerization. Adv. Mater. 2006, 18, 1188-1192. [CrossRef]

18. Ashfaq, A.; Clochard, M.-C.; Coqueret, X.; Dispenza, C.; Driscoll, M.S.; Ulański, P.; Al-Sheikhly, M. Polymerization Reactions and Modifications of Polymers by Ionizing Radiation. Polymers 2020, 12, 2877. [CrossRef]

19. Wu, D.; Ge, X.; Zhang, Z.; Wang, M.; Zhang, S. Novel One-Step Route for Synthesizing CdS/Polystyrene Nanocomposite Hollow Spheres. Langmuir 2004, 20, 5192-5195. [CrossRef]

20. Song, L.Y.; Wang, M.Z.; Cong, Y.H.; Liu, W.J.; Ge, X.W.; Zhang, Z.C. The mechanism of Co-60 gamma-ray radiation induced interfacial redox reaction in inverse emulsion and its application in the synthesis of polymer microcapsules. Polymer 2007, 48 , 150-157. [CrossRef]

21. Woodward, R.T.; Hight, C.; Yildiz, U.; Schaeffer, N.; Valliant, E.M.; Jones, J.R.; Stevens, M.M.; Weaver, J.V.M. Reversible aggregation of responsive polymer-stabilized colloids and the $\mathrm{pH}$-dependent formation of porous scaffolds. Soft Matter 2011, 7, 7560-7566. [CrossRef]

22. Yu, C.; Zhao, L.; Wang, S.; Cui, Z.; Peng, J.; Li, J.; Zhai, M.; Huang, J. One-step radiation-induced construction of multi-responsive self-assemblies using simple cyclic ethers. Soft Matter 2013, 9, 5959-5965. [CrossRef]

23. Seliverstov, A.F.; Ershov, B.G. Radiation-Chemical Transformations of Dicyclohexyl-18-Crown-6 in Aqueous-Solutions. High Energy Chem. 1988, 22, 173-176.

24. Janik, I.; Ulanski, P.; Hildenbrand, K.; Rosiak, J.M.; Von Sonntag, C. Hydroxyl-radical-induced reactions of poly(vinyl methyl ether): A pulse radiolysis, EPR and product study in deoxygenated and oxygenated aqueous solutions. J. Chem. Soc. Perkin Trans. 2000, 2, 2041-2048. [CrossRef]

25. Zhai, M.; Kudoh, H.; Wu, G.; Wach, R.A.; Muroya, Y.; Katsumura, Y.; Nagasawa, N.; Zhao, A.L.; Yoshii, F. Laser Photolysis of Carboxymethylated Chitin Derivatives in Aqueous Solution. Part 1. Formation of Hydrated Electron and a Long-Lived Radical. Biomacromolecules 2004, 5, 453-457. [CrossRef] [PubMed] 